Contents List available at VOLKSON PRESS

Intelligent Computing and Information Engineering (ICIE )

DOI : http://doi.org/10.26480/icie.01.2017.77.80

Journal Homepage: : https://www.intelcomp-design.com/

\title{
ANALYSIS ON MARKET CHANGE OF TOURISM DESTINATIONS IN ZHEJIANG PROVINCE BASED ON MARKET COMPETITION STATE MODEL
}

Yu Tong

He Yuan Polytechnic, He Yuan, Guangdong, China

*Corresponding author email: 86282557@qq.com

This is an open access article distributed under the Creative Commons Attribution License, which permits unrestricted use, distribution, and reproduction in any medium, provided the original work is properly cited

\section{ARTICLE DETAILS}

\section{Article History:}

Received 12 May2017

Accepted 12 July 2017

Available online 14 September 2017

Keywords:

market competition state,

Zhejiang Province, markets of tourism destinations.

\section{ABSTRACT}

In order to deeply study the tourism competitiveness of all cities in Zhejiang Province, based on the data related to the development of tourism industry in Zhejiang Province from 2006 to 2015, by using the tourism market competition state model, analysis is made on the inbound tourism and domestic tourism competition states of 11 cities. The results show that: the tourism industry in all cities of Zhejiang Province has unbalanced development; the market competition state of domestic tourism destinations in Zhejiang Province is obviously better than that of inbound tourism destinations, which shows that the markets of domestic tourism destinations have relatively stable and mature development.

\section{Introduction}

Zhejiang is an economy-prosperous province and a tourism-powerful province in China at the same time. The total income of tourism in Zhejiang Province increased from RMB169.01 billion to RMB713.91 billion in 2015, increased by 322.4\%, rapid in growth rate. However, all cities in Zhejiang Province have a very big difference in their development of tourism economy. For example, the total tourism income of Hangzhou Province in 2015 was RMB220.07 billion. Over the same period, the total tourism income of Quzhou City was only RMB28.78 billion with the wide gap between them being 6.6 times. This paper adopts tourism market competition state model, based on the relevant data of the Outline of Zhejiang Tourism Statistics (2006-2015), starts from the inbound tourism destinations and domestic tourism destinations and analyzes the tourism competition state of 11 cities of Zhejiang Province with a hope to provide reference for Zhejiang Province to formulate the regional tourism economic development strategy.

\section{RESEARCH METHOD}

Tourism market competition state model is adopted in this paper to analyze the changes in the markets of inbound tourism destinations and the markets of domestic tourism destinations in Zhejiang Province. China tourism scholars applied Boston's matrix method in studies on tourism markets, and established the tourism market competition state model, which can be shown by the following formula [1]:

$$
\begin{aligned}
& a_{i}=\frac{X_{i}^{t}}{\sum_{i=1}^{n} X_{i}^{t}} \times 100 \% \\
& \beta_{i}=\frac{X_{i}^{t}-X_{i}^{t-1}}{X_{i}^{t-1}} \times 100 \%
\end{aligned}
$$

$\alpha$ means market share, $\beta$ means market growth rate, and the combination of both constitute market competition state $\Omega$ ( $\alpha$, $\beta$ ), put $\Omega$ value in coordinate system, then the tourism market competition state can be reflected, see Figure 1 . See Table 1 for the type and characteristics of tourism market competition state [2]. 


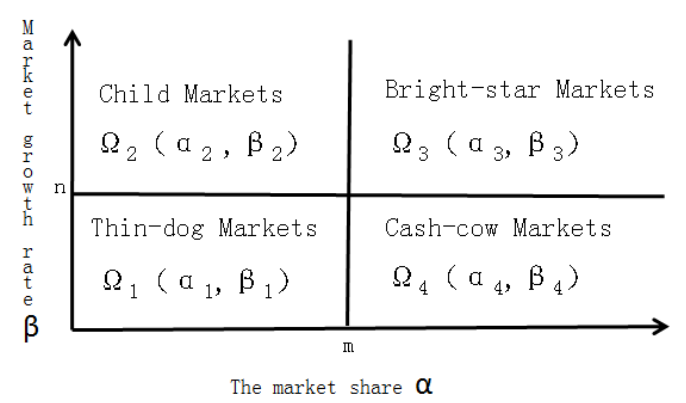

Figure 1: Schematic diagram of market competition state

Table 1: Basic characteristics and strategic direction of tourism market competition state

\begin{tabular}{|l|l|l|l|}
\hline Market type & $\begin{array}{l}\text { Classification } \\
\text { standard }\end{array}$ & Basic characteristics & Strategic choice \\
\hline $\begin{array}{l}\text { Bright-star } \\
\text { Markets }\end{array}$ & $\alpha \geq \mathrm{m}, \quad \beta \geq \mathrm{n}$ & $\begin{array}{l}\text { Double high in market share and growth rate, have considerable profit opportunities and good } \\
\text { development prospect. }\end{array}$ & $\begin{array}{l}\text { Expansionary } \\
\text { strategy }\end{array}$ \\
\hline $\begin{array}{l}\text { Cash-cow } \\
\text { Markets }\end{array}$ & $\alpha \geq \mathrm{m}, \quad \beta<\mathrm{n}$ & High market share, low growth rate, can recycle cash in large amount, but markets tend to saturation. & Harvesting strategy \\
\hline Child Markets & $\alpha<\mathrm{m}, \quad \beta \geq \mathrm{n}$ & Low market share, high growth rate, have relatively big development potential. \\
\hline Thin-dog Markets & $\alpha<\mathrm{m}, \quad \beta<\mathrm{n}$ & Double low in market share and growth rate, lie in a depressed state & Selective strategy \\
\hline
\end{tabular}

\section{EMPIRICAL ANALYSIS}

In order to make in-depth analysis on the change rule of tourism market competition state in Zhejiang Province, the market competition state of inbound tourism destinations and that of domestic tourism destinations in Zhejiang Province are divided into two periods, namely, Year 2006-2010 (hereinafter referred to as earlier stage) and Year 2011-2015 (hereinafter referred to as later period). The value of $\mathrm{m}$ and $\mathrm{n}$ shall be determined by using average method, and coordinate system is divided into 4 quadrants, formula (1) and (2) are used to calculate the value of competition state, Excel software is adopted to draw it into the two-dimensional coordinate system to form Figure 2, 3, 4 and 5, and empirical analysis is made according to these figures.

\subsection{Analysis on changes of market competition state of inbound tourism destinations in Zhejiang Province}

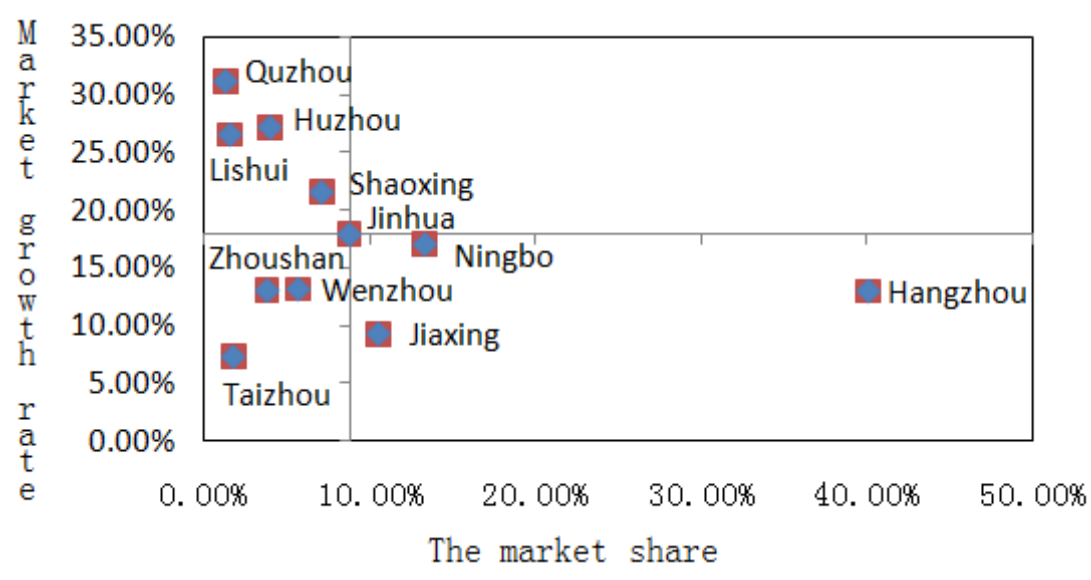

Figure 2: Market competition state of inbound tourism destinations in Zhejiang Province from 2006 to 2010

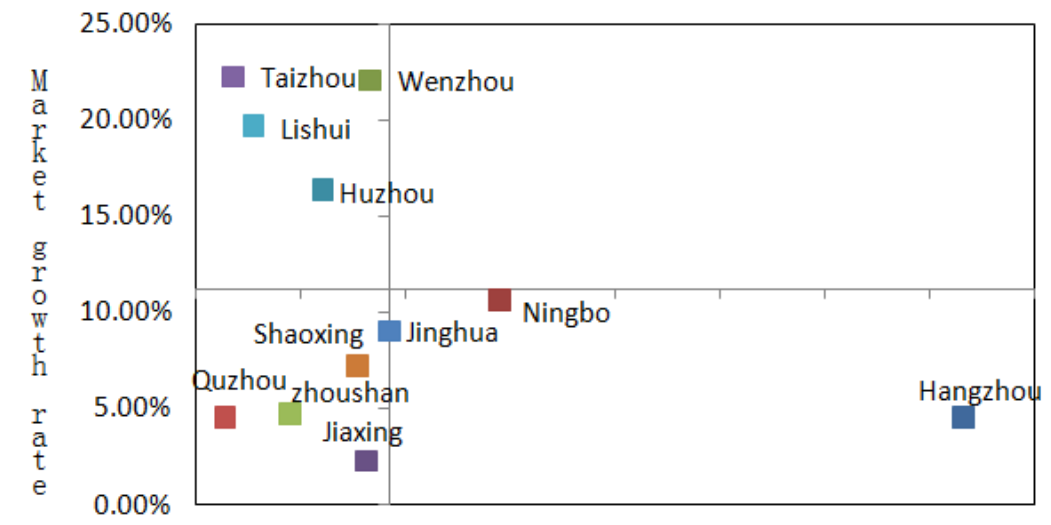

$0.00 \%$ 5. $00 \%$ 10. $00 \%$ 15. $00 \% 20.00 \% 25.00 \% 30.00 \% 35.00 \% 40.00 \%$

The market share

Figure 3: Market competition state of inbound tourism destinations in Zhejiang Province from 2011 to 2015 
It can be seen from Figure 2 and Figure 3 that, market competition state of inbound tourism destinations in Zhejiang Province has the following characteristics. Bright-star Markets lacked, no cities were Bright-star Markets in the earlier and later periods. Cash-cow Markets had no change in quantity, and there were 3 cities of this type in the earlier and later periods, accounting for 27.3\%. Hangzhou and Ningbo were always Cash-cow Markets, Jiaxing was depressed from Cash-cow Market in earlier period to Thin-dog Market in later period, while Jinhua jumped from Thin-dog Market to Cash-cow Market.

Thin-dog Markets and Child Markets accounted for the largest proportion, there were 4 cities, accounting for 36.4\%. Jinhua in earlier period jumped from Thin-dog Market in earlier period to Cash-cow Market in later period, Wenzhou and Taizhou restored from Thin-dog Markets to Child Markets, and Shaoxing and Quzhou depressed from Child Markets to Thin-dog Markets.

It can be seen from the above analysis that, inbound tourism destinations in Zhejiang Province had immature market development, Bright-star Markets lacked, and Thin-dog Markets and Child Markets accounted for too large proportion. Therefore, targeted measures need to be taken to improve the tourism competitiveness of the city.

\subsection{Analysis on changes of market competition state of domestic tourism destinations in Zhejiang Province}

It can be seen from Figure 4 and Figure 5 that, market competition state of domestic tourism destinations in Zhejiang Province has the following characteristics. Bright-star Markets were the least in quantity, only there was only 1 city in the earlier and later periods. However, there was a change in specific cities with Wenzhou in the early period and Taizhou in the later period.

Cash-cow Markets accounted for a large proportion, and there were 4 cities in earlier and later periods, accounting for $36.4 \%$. Hangzhou, Ningbo and Shaoxing were always Cash-cow Markets, Jiaxing was depressed from Cash-cow Market in earlier period to Thin-dog Market in later period, while Jinhua jumped from Thin-dog Market to Cash-cow Market. Child Markets accounted for a large proportion, there were 3 cities in earlier period, and Jinhua restored from Thin-dog Market to Child Market in later period to enable the Child Markets to become 4 markets in later period, accounting for $36.4 \%$.

Thin-dog Markets accounted for a small proportion, there were in earlier period, Jinhua became Child Market in later period, to enable the Thin-dog Markets to become 2 markets in later period, accounting for $18.2 \%$. It can be seen from the above analysis that, the market competition state of domestic tourism destinations in Zhejiang Province is obviously better than that of inbound tourism destinations, which shows that the markets of domestic tourism destinations have relatively stable and mature development.

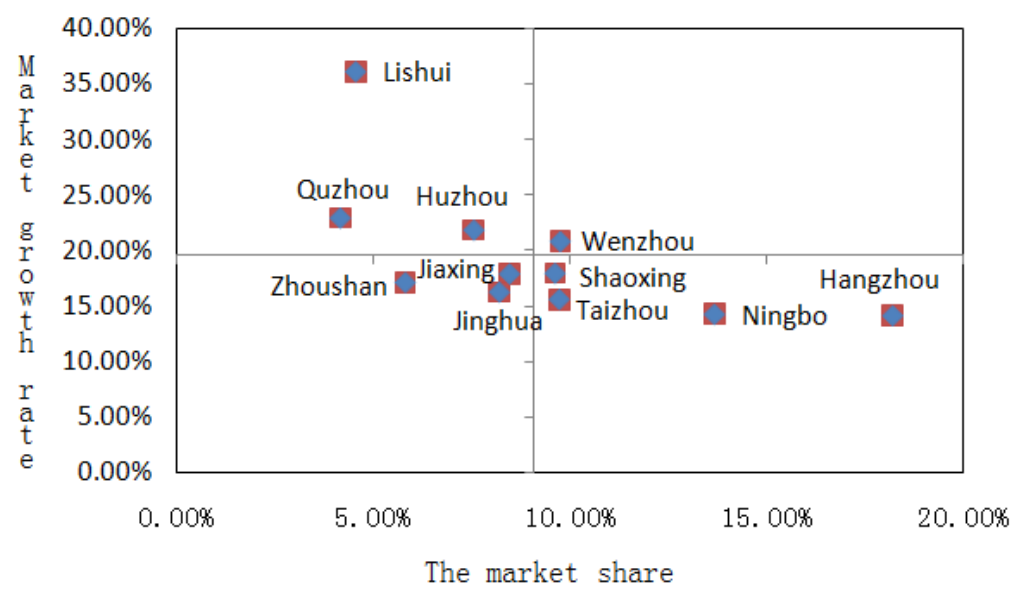

Figure 4: Market competition state of domestic tourism destinations in Zhejiang Province from 2006 to 2010

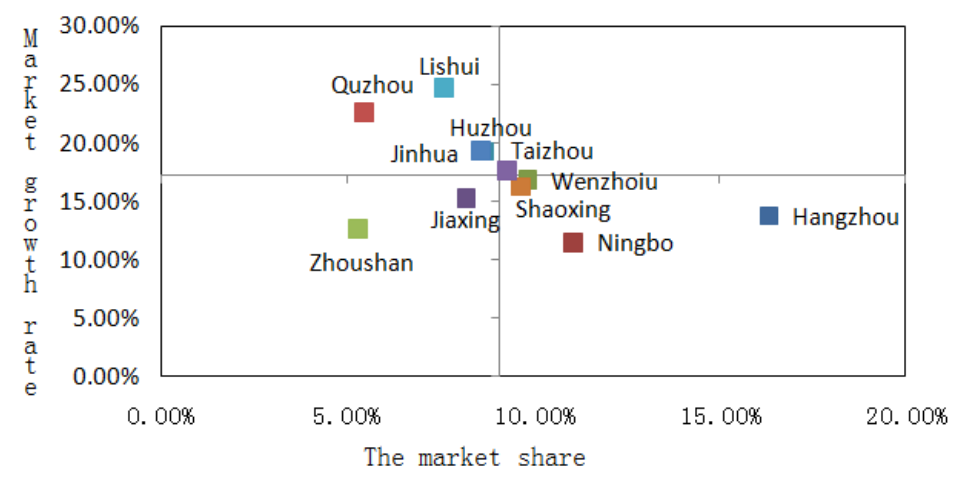

Figure 5: Market competition state of domestic tourism destinations in Zhejiang Province from 2011 to 2015

\section{CONCLUSIONS}

All cities in Zhejiang Province had unbalanced development in tourism, Hangzhou and Ningbo were always stable as Cash-cow Markets whether in inbound tourism or in domestic tourism. On the contrary, Zhoushan and Jiaxing were Thin-dog Markets in the two markets.

It can be seen from the above analysis that, the market competition state of domestic tourism destinations in Zhejiang Province is obviously better than that of inbound tourism destinations, which shows that the markets of domestic tourism destinations have relatively stable and mature development.

\section{REFERENCES}


[1] Jingyi, L., Gennian, S. 2002. Tourism Market Competition Model in China and its Application. Resources Science, 24, 91-96.

[2] Gennian, S. 2005. Analyses on Market Competition State of Chinese Inbound Tourism in New Century. Economic Geography, 25, 121-125. 